\title{
Multiple Sclerosis and Associated Diseases: A Relationship to Diabetes Mellitus
}

\author{
S. WARREN and K.G. WARREN
}

SUMMARY: One hundred multiple sclerosis (MS) patients and hospital controls were compared for coexisting illnesses, and other illnesses among their family members. The patients and controls were compared for allergy, migraine, and cancer among themselves and for a family history of these illnesses. The findings were negative. However a relationship was

RESUMÉ: Nous avons comparé chez 100 patients avec sclérose en plaques (SEP) et un nombre semblable de contrôles hospitaliers, la présence de maladies concomitantes ainsi que les maladies présentes chez les membres de leurs familles. En particulier furent scrutés l'incidence des allergies, migraines et cancer. Tous ces résultats furent négatifs. Cependant une found between multiple sclerosis and diabetes mellitus. More MS patients than controls were either diabetic or reported a blood relative with diabetes. MS patients who reported another blood relative with $M S$ were also more likely to report a family. history of diabetes mellitus than MS patients who had no other relative with multiple sclerosis.

relation fut trouvée entre la SEP et le diabète sucré, cette dernière entité étant plus fréquente chez les patients SEP et leurs familles. Il fut également montréque si un patient SEP a un autre cas de SEP dans sa famille, il a plus de chance d'avoir une histoire familiale de diabète sucré que ceux qui n'ont pas d'histoire familiale de $S E P$.
From the Department of Community Medicine, and the Multiple Sclerosis Research Clinic, Department of Medicine, University of Alberta, Edmonton, Alberta.

Reprint requests to Dr. Sharon Warren, Department of Community Medicine, University of Alberta, Edmoniton, Alberta, Canada T6G 2 G3.

\section{INTRODUCTION}

Multiple sclerosis (MS) tends to be a chronic disease, with a course extending over many years. Consequently there is ample opportunity for patients to develop other illnesses. The character of these illnesses may provide clues to the basic nature of MS itself. It is important to study associated diseases in both MS patients and their families because there appears to be a genetic predisposition to the disease. The predisposition is indicated by the familial aggregation of cases, and by the more common occurrence of certain histocompatibility antigens in patients.

This paper reports on the findings when MS patients and controls, or their families, were compared regarding three illnesses which the literature suggests may be associated with multiple sclerosis: allergy, migraine, and cancer. It also reports on a relationship that was found between multiple sclerosis and diabetes mellitus.

REVIEW OF THE LITERATURE

With the exception of periphlebitis retinae, uveitis and possibly allergic disorders, no relationship has been established between multiple sclerosis and any other disease. Studies by Ehrenteil et al (1952), McAlpine and Compston (1952), and Frövig et al (1967) have suggested that more MS patients, or their family members, than controls are subject to allergies. More MS patients than controls may experience migraine headaches prior to onset age (Watkins and Espir, 1969); and migraine in some individuals is associated with one or more forms of allergy.

Sibley et al (1978) have suggested that families who are high risk for MS may be at increased risk for cancer. However, this observation has not been confirmed. 
There appears to be no data linking multiple sclerosis to diabetes mellitus, although several researchers have reported an association between Friedreich's ataxia and diabetes (Andermann et al, 1976; Hewer and Robinson, 1968; Thoren, 1962). Andermann (1976) found that the incidence of diabetes mellitus in patients and grandparents of Friedreich's Ataxia patients was elevated 3 to 6 fold, compared to the general population. A history of diabetes was obtained for one or more second degree relatives in $37.1 \%$ of the families of Friedreich's ataxia patients.

\section{METHODS}

\section{Study Participants}

The muttiple sclerosis patients involved in the study were the first 100 who had their diagnoses confirmed at the University of Alberta MS Clinic after its opening in September 1978, and who agreed to participate. The majority, $66.0 \%(\mathrm{~N}=66)$, had developed their initial symptoms between the ages of $20-39 ; 25.0 \%$ had developed symptoms prior to age 20 , and only $9.0 \%(\mathrm{~N}=9)$ after age 39. Females outnumbered males by $2.3: 1$. Virtually all of the patients were Caucasian, except for one Oriental and one Métis. The majority, $97.0 \%(\mathrm{~N}=97)$, had spent most of their years before age 15 in a high risk MS zone. Sixty-eight per cent $(\mathrm{N}=68)$ of the MS patients were ambulatory.

Once the 100 cases had been interviewed, controls were sought from among patients on the neurological and rheumatology wards of the University of Alberta Hospital. Potential controls were matched to the first MS patient interviewed who resembled them for age, sex, race, and zone of residence prior to age 15 .

\section{Data Collection and Analysis}

The MS patients were interviewed in the Department of Community Medicine at the University of Alberta, and the controls were interviewed in the University Hospital. Both patients and controls were specifically asked whether they were subject to any allergies, to what they were allergic, and if the allergy(ies) were treated. MS patients were asked whether they had ever experienced migraine headaches prior to the onset of their symptoms; controls were asked whether they had experienced migraine prior to an artificial onset age, which was determined by the age when the case to whom they were matched had his/her first symptoms of MS. If an MS patient or control reported migraine headaches, they were asked to describe their symptoms in an effort to determine that the headaches were migraine.

Both MS patients and controls were asked whether they had ever had cancer, and what type. MS patients were also asked if they suffered from any coexisting disease, and were given examples such as hypertension, peptic ulcer, diabetes, tuberculosis and so on. The controls were asked if they suffered from any disease, coexisting the one for which they had been hospitalized, and were given the same list of examples as the cases.

Cases and controls were also asked to list any notable illnesses which had been experienced by immediate family members (grandparents, parents, siblings, or children); examples similar to those given for the cases and controls were suggested, including allergy and cancer. Number of siblings and children were recorded so that denominators could be established for both case and control family groups. Although they were not asked, both MS patients and controls were inclined to volunteer information on notable illnesses experienced by secondary blood relatives, such as aunts, uncles, cousins, nephews and nieces. Cousins, nephews and nieces were excluded from any analyses, because they were not full blood relatives. Aunts and uncles could only be included in any comparison where the illness was mentioned/not mentioned by an MS patient or control among their family members, since the numbers at risk were not known.

When illnesses other than allergy, migraine and cancer were scanned to detect any possible differences between cases and controls, or between their family members, there was none except for diabetes.

\section{RESULTS}

Case-Control Comparisons

\section{Allergy, Migraine, Cancer and Diabetes Mellitus}

Of the MS patients, $32.0 \%(\mathrm{~N}=32)$ reported that they were subject to one or more forms of allergy including: asthma, hay-fever, drug or food allergy, contact dermatitis and eczema. Of the controls, $33.0 \%(\mathrm{~N}=33)$ reported one or more forms of allergy. Sixteen percent $(\mathrm{N}=16)$ of the cases and $15.0 \%$ of the controls experienced migraine headaches prior to onset age. Only one MS patient and one control had had cancer. Three cases were diabetic; no control was.

\section{Case-Control Family Comparisons Allergy, Migraine and Cancer}

The cases reported 23 other immediate family members who were subject to one or more forms of allergy. The total number of grandparents, parents, siblings and children at risk in the case group was 1,088 , so that only $2.1 \%$ were subject to allergy. The controls reported 22 other family members with one or more forms of allergy. For the control group there were 1,146 family members at risk, so that $1.9 \%$ were subject to allergy. Only four cases reported an immediate family member who had experienced migraine headaches; two controls did.

The MS patients reported 77 immediate family members who had ever had cancer, or $7.1 \%$ of their total family members at risk. The controls reported that 61 , or $5.3 \%$ of their immediate family members had ever had cancer. Only one aunt was reported to have cancer by the cases; one uncle and an aunt by the controls. Fifty-four per cent $(\mathrm{N}=54)$ of the MS patients reported at least one blood relative who had had cancer, while $43.0 \%(\mathrm{~N}=43)$ of the controls did. Of the 18 MS patients who reported another blood relative with MS, $33.3 \%$ $(\mathrm{N}=6)$ of them reported at least one blood relative who had had cancer, for a total of 16 . Of the 82 MS patients who reported no other relative with MS, $58.5 \%(\mathrm{~N}=48)$ reported at least one blood relative who had had cancer, for a total of 62 . 


\section{Diabetes Mellitus}

With regard to diabetes, $30.0 \%$ $(\mathrm{N}=30)$ of the MS patients reported having a grandparent, parent, sibling or child with the disease; 42 family members were reported. Thus, out of 1,088 family members at risk, $3.9 \%$ were reported to be diabetic. The cases reported another 8 aunts or uncles with diabetes, and 3 cousins, nephews or nieces with that disease. Of the hospital controls, $20 \%(\mathrm{~N}=20)$ reported a grandparent, parent, sibling or child with diabetes; 29 family members were reported. Thus out of 1,146 family members at risk, $2.5 \%$ were reported as diabetic. The controls reported 4 other aunts or uncles with diabetes, but no cousins, nephews or nieces with that disease. Although there was no remarkable difference between the case and control families in terms of the proportion at risk who were diabetic, there was a significant difference between the proportion of cases and controls who were either diabetic themselves or reported at least one family member with diabetes (Table 1).

Of the $18 \mathrm{MS}$ patients from high risk MS families, $66.7 \%(\mathrm{~N}=12)$ were either diabetic themselves or had at least one blood relative with diabetes. The total number of diabetics reported by them was 21 . Of the $82 \mathrm{MS}$ patients who had no other relative with $\mathrm{MS}, 30.5 \%$ $(\mathrm{N}=25)$ reported at least one family member with diabetes. The total number of diabetics reported by them was 34. These figures indicate a statistical association between familial multiple sclerosis and diabetes mellitus (Table 2).

\section{DISCUSSION \\ Summary of Findings}

The findings of this study do not support any association between multiple sclerosis and allergy, migraine or cancer. There was no association whether MS patients alone were compared to controls, or the families of MS patients were compared to control families. There was no association between familial multiple sclerosis and cancer.

More MS patients than controls were either diabetic themselves or reported at least one blood relative with that disease, when secondary relatives (aunts and uncles only) were included in the comparison. Families who were high risk for MS also had an increased risk for diabetes mellitus.

\section{Limitations on the Data}

No attempt was made to verify the information given by MS patients and controls. However allergy, cancer and diabetes are familiar illnesses, often identifiable by some obvious symptom or the treatment adopted. It seems likely that the more severe cases among both the MS patients' families and the controls' families would have been reported accurately by them. On the other hand some mild or unobtrusively treated cases among family members may have gone unremarked by the MS patients or controls. In addition mild or isolated allergy, or borderline diabetes, may never have been diagnosed in some of the MS patients, the controls, or among their family members.

There were only $18 \mathrm{MS}$ patients who reported having at least one other blood relative with multiple sclerosis, so that it would be difficult to draw any conclusion about a possible association between familial multiple sclerosis and either cancer or diabetes. The presence of multiple sclerosis in their relatives was not verified; however the percentage of MS patients reporting another blood relative with $\mathrm{MS}$ is similar to that found in Sibley's study of MS and cancer (1978).

\section{A Possible Relationship Between Multiple Sclerosis and Diabetes Mellitus}

The association found between MS and diabetes may support the possibil-

TABLE 2

Familial Multiple Sclerosis And A Family History Of Diabetes Mellitus

Comparison Of MS Cases And Controls On The Proportion Who Were Diabetic Or Reported At Least One Family Member With Diabetes

\begin{tabular}{|c|c|c|c|c|}
\hline & \multicolumn{2}{|c|}{ MS Cases } & \multicolumn{2}{|c|}{ Controls } \\
\hline & $\%$ & $\mathbf{N}$ & $\%$ & $\mathbf{N}$ \\
\hline $\begin{array}{l}\text { Diabetic and/or report } \\
\text { at least one blood } \\
\text { relative with diabetes }{ }^{1}\end{array}$ & 37.0 & 37 & 24.0 & 24 \\
\hline No diabetes & 57.0 & 57 & 75.0 & 75 \\
\hline \multirow[t]{2}{*}{ Missing or excluded } & 6.0 & $6^{2}$ & 1.0 & $1^{3}$ \\
\hline & 100.0 & 100 & 100.0 & 100 \\
\hline
\end{tabular}

$\mathrm{x}^{2}=4.6,1 \mathrm{df} . \mathrm{p}<.05$

1. Aunts and uncles counted; a reference to "runs in family" counted as one; but cousins, nephews and nieces not counted.

2. One MS patient reported that a relative had some medical problem related to "sugar" consumption but could not specify whether the illness was a form of diabetes; three.MS patients were adopted; two MS patients had only a nephew with diabetes.

3. One control was adopted.
MS Patients with

at least one other

blood relative

having MS

$\% \quad \mathbf{N}$

Family Member(s)

with Diabetes

\begin{tabular}{|c|c|c|c|c|}
\hline Yes $^{1}$ & 66.6 & 12 & 30.5 & 25 \\
\hline No & 33.4 & 6 & 62.2 & 51 \\
\hline $\begin{array}{l}\text { Missing or } \\
\text { excluded }^{2}\end{array}$ & 0.0 & 0 & 7.3 & 6 \\
\hline Total & $100.0 \%$ & 18 & $100.0 \%$ & 82 \\
\hline
\end{tabular}

$\mathrm{X}^{2}=6.9,1 \mathrm{df}, \mathrm{p}<.01$

1. Aunts and uncles counted; a reference to "runs in family" counted as one; but cousins, nephews and nieces not counted.

2. See Table 1: Footnote 2. 
ity that some metabolic disorder contributes to the development of multiple sclerosis.

Because several authors have suggested a relationship between multiple sclerosis and milk ingestion, Verdy (1977) tested the effect of milk load on blood glucose and serum insulin concentrations in 13 MS cases and 11 controls. He found no difference in either and remarked that if milk plays a role in the etiology of MS, it does not do so through the abnormal secretion of insulin.

However, it remains possible that milk plays some role, since areas of the world where milk consumption is high are also high incidence zones for MS (Butcher, 1976; Agranoff and Goldberg, 1974). Swank et al (1952) observed that in Norway the geographic distribution of multiple sclerosis could be correlated to the chief occupation of a district. The disease was most prevalent in farming and dairying areas. Swank has suggested that the ingestion of fats, especially milk and animal fats, may be among the factors which contribute to the development of multiple sclerosis in susceptible persons. The relevance of fatty acid metabolism to multiple sclerosis has been reviewed by Merton and Meade (1977). Some authors have suggested that dietary excesses of certain fats may cause errors in the development of myelin, perhaps early in life, and these may render the myelin unstable or susceptible to attack (Alter, 1977; Dick, 1976). Abnormalities in fat metabolism have been observed in diabetic patients with relatively mild insulin deficiency (Sherwin and Felig, 1978).

Milk is also an excellent dietary source of calcium. Goldberg (1974) and Craelius et al (1978) have presented evidence that adequate supplies of vitamin D and calcium are required for proper myelin development. High risk areas of multiple sclerosis correlate well with areas of the world where dairy consumption is high. They are also frequently among the least sunny or colder areas of the world (Visscher et al, 1977; Leibowitz et al, 1973; Kurland and Reed, 1964; Limburg, 1950), thus implying the potential for a vitamin $\mathrm{D}$ deficiency among their populations. Craelius' interest in the possible role of vitamin
$\mathrm{D}$ and calcium in myelin development apparently stems from his conviction that MS and dental caries may share certain etiological factors (1978). He has observed, for example, that the prevalence of MS in 45 countries or areas correlates well with the frequencies of decayed, missing and filled teeth among children of school age in those locations.

The geographical distribution of rickets in the early 20 th century also bore some similarity to multiple sclerosis (Hess, 1929). Kloster (1931) demonstrated the important interplay of vitamin $\mathrm{D}$ and calcium intake in the prevention of rickets. His study in Finmark also supported the antirachitic property of fish oils, and their importance in influencing calcium absorption as a vitamin D supplement. In Swank's study of Norway (1952), the prevalence of MS was consistently lower in the fishing districts than in the farming and dairying areas.

Several recent studies have examined calcium metabolism in diabetes mellitus. A study by Gertner et al (1979) reports that urinary calcium excretion is increased, and skeletal density reduced in juvenile-onset diabetes. A study by Raskin et al (1978) has associated uncontrolled diabetes with an excessive urinary loss of calcium in adult diabetics. Hoskins et al (1979) found a significant decrease in active uptake of calcium by the kidney in streptozotocindiabetic rats, considerably earlier than evidence of nephropathy.

Discussion of a possible common factor in multiple sclerosis and diabetes mellitus is merely speculative; and the possibility of a relationship between these two diseases itself remains to be confirmed.

\section{ACKNOWLEDGEMENTS}

Funding for this project was provided by the Special Services and Research Committee. University of Alberta Hospital; the Association of Canadian Travellers, Alberta Division; and the Multiple Sclerosis Society of Canada.

\section{REFERENCES}

AGRANOFF, B.W. and GOLDBERG, D. (1974). Diet and the geographical distribution of multiple sclerosis. Lancet, 2: 1061-67.

ALTER, M. (1977). Clues to the cause based upon the epidemiology of MS. In Multiple Sclerosis. A Critical Conspectus, Field, E.J. (Ed.) University Park Press, Baltimore.
ANDERMANN, E., REMILLARD, G.M., GOYER, G. et al. (1976). Genetic and family studies in Friedreich's Ataxia. Can. J. Neurol. Sci., 3: 287-301.

BUTCHER, J. (1976). The distribution of multiple sclerosis in relation to the dairy industry and milk consumption. N.Z. Med. J., 83: 566-73.

CRAELIUS, W. (1978). Comparative epidemiology of multiple sclerosis and dental caries. J. Epid. Comm. Med., 32: 155-65.

CRAELIUS, W., NEWBY, N. and THOMAS, F.C. (1978). Central myelination in vitro: effect of reduced calcium and magnesium. Neurological Absts.

DICK, G. (1976). The etiology of multiple sclerosis. Proc. R. Soc. Med. 69: 611-15.

EHRENTHEIL, O., SCHULMAN, $M$. and ALEXANDER, L. (1952). Role of food allergy in multiple sclerosis. Neurology, 2: 412-27.

FROVIG, A., PRESTHUS, J. and SPONHEIM, N. (1967). The significance of allergy in the etiology and pathogenesis of multiple sclerosis. Acta Psych. (Scand.), 43: 215-25.

GERTNER, J., HORST, R. and TAMBORLANE, W. (1979). Mineral metabolism and vitamin D status in juvenile diabetics: changes following normalization of plasma glucose. Presented at 39th Annual Meeting of the American Diabetes Association, Los Angeles.

GOLDBERG, P. (1974). Multiple sclerosis: vitamin $D$ and calcium as environmental determinants of prevention. Parts I and II. Internat. J. Environ. Studies, 6: 19-27, 12129.

HESS, A. Rickets, Osteomalacia and Tetany. Lea and Febiger, Philadelphia, 1929.

HEWER, R.L. and ROBINSON, M. (1968). Diabetes mellitis in Friedreich's ataxia. J. Neurol. Neurosurg. Psychi., 31: 226-31.

HOSKINS, B., FEIBELMAN, R., LOURY, A. et al. (1979). Effectiveness of insulin therapy on altered renal calcium transport in diabetic rats. Diabetes, 28: 1088-94.

KLOSTER, J. (1931). Distribution and frequency of rickets in one fishery district of Finmark and relation to diet disorder. Acta Paed., 12 (Suppl. 3): 1.

KURLAND, L. and REED, D. (1964). Geographic and climatic aspects of multiple sclerosis. A.J.P.H. 54: 588-97.

LEIBOWITZ, U. and ALTER, M. (1973). Multiple Sclerosis: Clues to its Cause. North Holland, Amsterdam.

LIMBURG, C. (1950). The geographic distribution of multiple sclerosis and its estimated prevalence in the U.S. In Multiple Sclerosis and the Demyelinating Diseases. Williams and Wilkins, Baltimore.

MCALPINE, D. and COMPSTON, M.D. (1952). Some aspects of the natural history of disseminated sclerosis. Q.J. Med., 21: 13567.

MERTON and MEADE, C.J. (1977). Relevance of fatty acids in Multiple Sclerosis. Brit. Med. Bull., 33: 67-74.

RASKIN, P., STEVENSON, M., BARILLA, $D$. et al (1978). The hypercalciuria of 
diabetes mellitus: its amelioration with insulin. Presented at the 38th Annual Meeting of the American Diabetes Association, Boston.

SHERWIN, R. and FELIG, P. Pathophysiology of diabetes mellitus. In Symposium on Diabetes Mellitus. Medical Clinics. of N.A. S. Poldolsky (Ed.). W.B. Saunders Co.. Philadelphia. 1978.

SIBLEY, W.A.. BAMFORD, D. and LAQUNA. F. (1978). Anamnestic studies in multiple sclerosis: a relationship between familial multiple sclerosis and neoplasia. Neurology, 28: 125-29.

SWANK, R.L., LERSTED, O., STROM, A. and BACKER, J. (1952). Multiple Sclerosis in rural Norway. New Engl. J. Med., 246: $721-28$.

THOREN, C. (1962). Diabetes mellitus in Friedreich's Ataxia. Acta Paed., Suppl. 135: 239-47.
VISSCHER, B., DETELS, R., COULSON, A. et al. (1977). Latitude, migration and the prevalence of multiple sclerosis. Amer. J. Epid., 106: 470-75.

VERDY, M. (1977). Multiple sclerosis and milk. C.M.A.J., 9: 117 .

WATKINS, S. and ESPIR, M. (1969). Migraine and multiple sclerosis. J. Neuro. Neurosurg. Psychiat., 32: 35-37. 